\title{
Malaria Parasitaemia in Children With Protein Energy Malnutrition In North Central Nigeria: A Case Control Study.
}

\author{
Saka Aishat $\mathrm{O}^{1}$, Saka Mohammed $\mathrm{J}^{2}$, Adeboye Mohammed $\mathrm{AN}^{3}$, Mokuolu \\ Olugbenga $\mathrm{A}^{4}$, Abu-Saeed Muhammad Buhari ${ }^{5}$, Abu-Saeed Kamaldeen ${ }^{6}$ \\ ${ }^{I}$ Consultant Paediatrician/Lecturer 1,Dept Of Paediatrics, University Of Ilorin Teaching Hospital, Ilorin. \\ Nigeria. \\ ${ }^{2}$ Consultant Community Physician/Lecturer1,Dept. Of Epidemiology And Community Health, University Of \\ Ilorin Teaching Hospital, Ilorin. Nigeria. \\ ${ }^{3}$ Consultant Paediatrician/Lecturer 1, Dept Of Paediatrics, University Of Ilorin Teaching Hospital, Ilorin. \\ Nigeria. \\ ${ }^{4}$ Consultant Paediatrician/Professor, Dept Of Paediatrics, University Of Ilorin Teaching Hospital, Ilorin. \\ Nigeria. \\ ${ }^{5}$ Scientific Officer, Microbiology Dept., University Of Ilorin Teaching Hospital, Ilorin. Nigeria. \\ ${ }^{6}$ Superintendent Pharmacist/Head Of Research Unit, Peace Standard Pharmaceuticals, Ilorin. Nigeria.
}

\begin{abstract}
Background-Malaria and Protein-Energy-Malnutrition (PEM) are two major causes of childhood mortality in sub-Saharan Africa. Malaria can predispose a child to PEM and the reverse may also be true. Recent studies have presented inconsistent findings about nutritional status and the occurrence of malariathus. The goal of this study was to evaluate the association between PEM and malaria parasitaemia if any.

Methods-A case control study in which 90 children diagnosed for PEM (aged 6 -59 months), and another well nourished 90 children age and sex-matched controls were evaluated for malaria parasitaemia. A semi-structured proforma was used to obtain relevant information on the children's socio-demographic characteristics, nutritional indices amongst others. Venous blood sample blood was collected and thick and thin blood film were prepared and viewed under the microscope.

Results-Malaria parasitaemia was present in 82 (91.1\%) of malnourished group and $12(13.3 \%)$ of the well nourished group $(p<0.05$ OR=66.62). Malaria parasitemia was highest in those with kwashiorkor and marasmic kwashiorkor compared with underweight. These differences were statistically significant $(p<0.05)$.

Conclusion and Recommendation-The study demonstrates that malnourished children have higher degree of malaria parasitaemia and are at risk of malaria. It also shows that severe forms of malnutrition are associated with heavier malaria parasitaemia.

It is therefore recommended that all malnourished children should have access to use of Insecticide Treated Nets (ITN), malaria chemoprophylaxis as well as empiric treatment of malaria in endemic areas where access to malaria parasite diagnosis is difficult.
\end{abstract}

Keywords: Severe Protein energy malnutrition(PEM), Malaria Parasitaemia,InsecticideTreated Nets (ITN).

\section{Introduction}

Protein energy malnutrition (PEM) is a leading cause of morbidity and mortality among children under five worldwide, especially in the developing countries ${ }^{1}$. Causes of severe morbidities as well as mortality usually results from complications associated with the condition as well as the existence of other co-morbidities. The presence of Infection is a common cause of death among children with protein energy malnutrition. Common causes of infection in them include bacteria, viral and parasitic infections. A common parasitic infection which can occur as co-morbidity is Malaria. ${ }^{1}$

Malaria and under-nutrition are the two major causes of childhood mortality in sub-Saharan Africa $^{2}$.Complex relationships exist between malaria and malnutrition. Complicated malaria can predispose a child to malnutrition when while a malnourished child can be predisposed to be infected with malaria ${ }^{2,3}$. Malaria like PEM is commonly associated with poverty; both can also be a cause of poverty and are major hindrance to economic development ${ }^{1}$.Both have common effects such as chronic anemia, impaired growth, and delayed cognitive development on children ${ }^{1,2}$.

The impact of malnutrition on malaria outcome as well as that of malaria on nutritional outcome has been studied by previous authors ${ }^{2-9}$.A number of observations have indicated a deleterious effect of malaria on nutritional status, ${ }^{2,3}$ while earlier observational studies provide some evidence of protective effect of undernutrition against malaria ${ }^{4-6}$. However, more recent studies have presented inconsistent findings that nutritional status was not associated with the occurrence of malaria ${ }^{7-9}$.The outcome of malaria on the nutritional status of 
affected children has also been clearly defined ${ }^{3}$. However the effect of nutritional status on host resistance to acquisition and progression of malaria is still not clearly defined. A clear relationship has to be defined between these very important causes of childhood morbidity and mortality in this part of the world. Thus, the goal of this study was to evaluate whether malnutrition is associated with increased or decreased malaria parasitaemia.

\section{METHODS}

This was a case control study in which subjects were children diagnosed with PEM with ages between 6 to59 months old and controls were children with normal nutritional status admitted to paediatric ward of the University of Ilorin Teaching hospital which is located in the North Central zone of Nigeria. PEM patient were classified based upon the Wellcome classification ${ }^{10}$.

Clinical examination and anthropometric measurements such as weight and height were carried out among the subjects by the investigator. The weight was measured to the nearest 0.1 kilogram using standardized scales while the length was measured to an accuracy of 0.1 meter using an infantometer for children less than 2 years and a stadiometer for height among children older than 2 years children.

A semi-structured questionnaire was used to obtain information from the subjects using an interview method. Relevant information on the children's socio-demographic characteristics, nutritional indices and laboratory findings were documented.

Socio-economic index scores were awarded to the occupations and educational attainments of their parents or caregivers using the Oyedeji socio-economic classification scheme ${ }^{11}$. Socio economic class I and II are the upper socio-economic class, class III is the middle class while socio economic class IV and V are the lower socio-economic class ${ }^{11}$.

The study was approved by the Ethics and Research Committee of the University of Ilorin Teaching Hospital. ${ }^{21}$

\section{Sample collection and analysis}

Under strict aseptic conditions, after cleaning the blood collection site thoroughly with $70 \%$ alcohol, 1 mili liter of venous blood was collected by venepuncture using a fixed hypodermic needle.

Blood films were prepared both thin and thick films in the standard manner. The slide was then air dried and the films were then fixed with methanol or ethanol on a standing rack. After about three minutes, staining was done with $10 \%$ Giemsa stain diluted to $\mathrm{pH}$ of 7.2 with phosphate buffer for 10 minutes after which clean water was used to wash the stains.

\section{Reporting the thick film}

The report of the thick film was done using the protocol described by Cheesbrough $\mathrm{M}^{12}$. Briefly, a drop of immersion oil was applied to the film and viewed under microscope using the 100x objective to examine at least 100 high power fields (HPF). The finding was reported as:

1-10 parasites per 100HPF was recorded as +

11-100 parasites per 100HPF as ++

1-10 parasites in one HPF as +++

More than 10 parasites in one HPF as ++++

Data entry and analysis were carried out with a micro-computer using the Epi info version 3.5 (2008) software packages. $\mathrm{P}$ value was set at $<0.05$ for significant relationships. Odd ratio interpretation was $1=$ risk in the two group, $<1=$ lesser risk in the first group and $>1=$ higher risk in the first group.The malnourished children form the first group while the controls formed the second group.

\section{RESULTS}

A total of 90 children with PEM and 90 well nourished children were studied. Of the 90 children with PEM, $59(65.6 \%)$ were males and $31(34.4 \%)$ were females, (M: F ratio 1.9:1). While of the 90 well nourished ones, $53(58.9 \%)$ were males and 37(41.1\%) were females (M: F ratio1.4:1.) $(p=0.36)$

The mean age of the children with PEM was $22.7 \pm 14.4$ months while the mean age of the control was $29.3 \pm$ 16.9 months. $(p=0.08)$.

Children with PEM were mainly from low socio economic class and there was a statistical significant difference in the social economic status of the malnourished group and the well nourished group $(p=0.00001)$ as shown in Table 1.

Fifty $(55.6 \%)$ children with PEM were underweight, 21(23.3\%) had marasmus, 11 (12.2\%) had marasmic-kwashiokor and $8(8.8 \%)$ had kwashiorkor. (See-Table II).

Of the malnourished $82(91.1 \%)$ had malaria parasitaemia compared with $12(13.3 \%)$ of the well nourished ones. There was a statistical significant difference. $(\mathrm{p}=0.0000)$. (See Table III)

All the $11(100 \%)$ children with kwashiorkor as well as all the $8(100 \%)$ with marasmic-kwashiokor were positive for malaria parasitaemia. Nineteen $(90.5 \%)$ of the 21 children with Marasmus and $44(88.0 \%)$ of underweight children also had malaria parasitaemia. Each of these compared with the well nourished children 
showed statistically significant differences. $(p<0.05)$ The degree of parasitemia in each of the types of PEM is as shown in the Table IV below.

\title{
IV. DISCUSSION
}

Malaria and PEM are common in sub-Saharan Africa, it is therefore important to understand the relationship which exists between them because of its enormous public health importance.

This present study shows that over ninety percent of the malnourished children studied had malaria parasitaemia. There was also a significant difference when the density of parasitemia of the malnourished was compared with that of well nourished children.The odds ratio further strengthen this fact as the findings derived demonstrate a higher risk of malaria among the malnourished children.Our findings shows that undernourished children experienced more, not less, malaria parasitaemia when compared to well nourished children. This finding is similar to previous studies.A more recent study in Ibadan Nigeria by Olumese $e a^{13}$ also reported that malnutrition was associated with severe forms of malaria.

In Sudanese children, el Samani et al recorded that malaria was more often in malnourished than in adequately nourished children. ${ }^{14}$ Other studies from Tanzania, Chad, Zaire and Kenya ${ }^{15-18}$ also confirm the greater risk of malaria among children with poor nutritional status. Another longitudinal study from Vanuatu ${ }^{19}$ supports the claim that malnutrition predisposes the host to malaria infection. However none of these studies demonstrated if malaria preceded malnutrition or vice versa.

The study also shows that the degree of parasitaemia also varied among the various classes of malnourished children. Kwashiokor and marasmic-Kwashiokor which were the most severe forms of malnutrition had higher density of malaria parsitaemia. These findings show that the host resistance to malaria is poor as the more severe forms which are associated with diminished immunity experience higher intensity of the malaria parasite. It also shows that more severe forms of malnutrition might likely experience severe forms of malaria as they are associated with higher degree of parasitaemia. This finding is also in consonance with previous findings such as the one by Ahmad et al which showed a positive correlation between the level of parasitemia and weight-for-age in children infected with either P. falciparum or $P$. vivax. ${ }^{20}$

\section{CONCLUSION}

The study clearly demonstrates that malnourished children have a higher degree of malaria parasitaemia and are at a higher risk of malaria. It also shows that more severe forms of malnutrition are associated with a higher degree of malaria parasitaemia.

\section{RECOMMENDATION}

The finding of this study thus recommends that all malnourished children should have access to the use of Insecticide Treated Nets (ITN), malaria chemoprophylaxis as well as recommends empiric treatment of malaria in children with malnutrition in areas where the access to malaria parasite diagnosis is complicated. This we opine will go a long way in reducing mortality as well as increase the survival of children with PEM who often have malaria as aco-morbidity. It also recommends that further studies on the relationship between malaria and protein energy malnutrition should be carried out by other research work

\section{Acknowledgment}

We are highly grateful to the authors who have contributed to the funding, writing and review of this manuscript for publication. We are also grateful to the University of Ilorin Teaching hospital where the research work was carried out. We are also grateful to Mr. Olatunbosun of the Haematology department of the same hospital, who assisted in blood sample analysis.

\author{
Abbreviation \\ PEM Protein energy malnutrition. \\ MP Malaria parasite \\ HPF High power fields.
}

\section{References}

1. Ehrhardt S, Burchard GD, Mantel C, Cramer JP, Kaiser S, et al. Malaria, anaemia, and malnutrition in African children-defining intervention priorities. J Infect Dis.2006;194:108-114

2. Breman JG. The ears of the hippopotamus: manifestations, determinants, and estimates of the malaria burden. Am J Trop Med Hyg. 2001;64:1-11.

3. Snow RW, Molyneux CS, Njeru EK, Omumbo J, Nevill CG, et al. The effects of malaria control on nutritional status in infancy. Acta Trop. 1997;65:1-10

4. Murray MJ, Murray AB, Murray MB, Murray CJ. The adverse effect of iron repletion on the course of certain infections. Br Med J. 1978;2:1113-1115 
5. Hendrickse RG, Hasan AH, Olumide LO, Akinkunmi A. Malaria in early childhood. An investigation of five hundred seriously ill children in whom a "clinical" diagnosis of malaria was made on admission to the children's emergency room at University College Hospital, Ibadan. Ann Trop Med Parasitol. 1971;65:1-20.

6. Murray MJ, Murray NJ, Murray AB, Murray MB. Refeeding-malaria andhyperferraemia. Lancet.1975;1:653-654.

7. DeenJL, Walraven GE, von Seidlein L. Increased risk for malaria in chronically malnourished children under 5 years of age in rural Gambia. J Trop Pediatr.2002;48:78-83.

8. Friedman JF, Kwena AM, Mirel LB, Kariuki SK, Terlouw DJ, et al. Malaria and nutritional status among pre-school children: results from cross-sectional surveys in western Kenya. Am J Trop Med Hyg. 2005;73:698-704.

9. Snow RW, Byass P, Shenton FC, Greenwood BM. The relationship between anthropometric measurements and measurements of iron status and susceptibility to malaria in Gambian children. Trans R Soc Trop Med Hyg. 1991;85:584-589.

10. Wellcome Trust International Working Party. Classification of Infantile Malnutrition. Lancet .1970;2:302-303

11. Oyedeji GA. Socio-economic and cultural background of hospitalized children in Ilesha. Nig J Paediatr .1985;12: 111-7.

12. Cheesbroug M. Detecting and Identifying Malaria in Blood Film In: District Laboratory Practice in Tropical Countries part I. Cambridge University Press 1998; 245-51.

13. Olumese PE, Sodeinde O, Ademowo OG, Walker O. Protein energy malnutrition and cerebral malaria in Nigerian children. J TropPediatr . 1997;43: 217-219.

14. ElSamani FZ, Willett WC, Ware JH. Nutritional and socio-demographic risk indicators of malaria in children under five: acrosssectional study in a Sudanese rural community. J Trop Med Hyg 1987; 90: 69-78

15. Mbago MCY, Namfua PP. Some determinants of nutritional status of one to four year old children in low-income urban areas of Tanzania. J Trop pediatr .1991;38: 299-306

16. Renaudin P, Lombart JP: Anemia in infants less than 1 year old in Moundou, Chad: prevalence and etiology (in French). Med Trop (Mars) 1994; 54: 337-342.

17. Tshikuka J, Gray-Donald K, Scott M, Olela KN. Relationship of childhood protein-energy malnutrition and parasite infections in an urban African setting. Trop Med Int Health.1997;2: 374-382.

18. Nyakeriga AM, Troye-Blomberg M, Chemtai AK, et al. Malaria and nutritional status in children living on the coast of Kenya. Am J ClinNutr.2004;80: 1604-1610.

19. Williams TN, Maitland K, Phelps L, et al. Plasmodium vivax: a cause of malnutrition in young children. QJM.1997;90: 751-757.

20. Ahmad SH, Moonis R, Shahab T, et al. Effect of nutritional status on total parasite count in malaria. Indian J Pediatr.1985;52: $285-288$.

21. University of Ilorin Teaching Hospital ethical approval;UITH/CAT/189/11/784.2008.

Table 1: The Socio-Demographic Characteristics Of The Malnourished And Controls.

\begin{tabular}{|c|c|c|c|c|}
\hline Variable & $\begin{array}{l}\text { PEM } \\
(n=90)\end{array}$ & $\begin{array}{l}\text { Controls } \\
(n=90)\end{array}$ & $\chi^{2}$ & $P$ \\
\hline $\begin{array}{l}\text { Age (month) } \\
\text { Range } \\
\text { Mean } \pm \text { S.D }\end{array}$ & $\begin{array}{l}9.0-59.0 \\
22.7 \pm 14.4\end{array}$ & $\begin{array}{l}6.0-59.0 \\
29.3 \pm 16.9\end{array}$ & $\mathrm{t}=7.95$ & 0.08 \\
\hline $\begin{array}{l}\text { Gender } \\
\text { Male } \\
\text { Female }\end{array}$ & $\begin{array}{l}59(65.6 \%) \\
31(34.4 \%)\end{array}$ & $\begin{array}{l}53(58.9 \%) \\
37(41.1 \%)\end{array}$ & 0.85 & 0.356 \\
\hline $\begin{array}{l}\text { Social Economic Class } \\
\text { I } \\
\qquad \begin{array}{l}\text { II } \\
\text { III } \\
\text { IV } \\
\text { V }\end{array}\end{array}$ & $\begin{array}{l}2(2.2) \\
6(6.8) \\
26(28.8) \\
38(42.2) \\
18(20.0)\end{array}$ & $\begin{array}{l}4(4.4) \\
27(30.0) \\
35(38.9) \\
16(17.8) \\
8(8.9)\end{array}$ & 28.17 & 0.000012 \\
\hline
\end{tabular}

Table 2: Distribution Of Types Of Protein Energy Malnutrition

\begin{tabular}{lll}
\hline Type of PEM & Frequency & Percentage \\
\hline Kwashiokor & 8 & 8.9 \\
Marasmus & 21 & 32.2 \\
Marasmic- Kwashiokor & 11 & 12.2 \\
Underweight & 50 & 55.6 \\
Total & 90 & 100 \\
\hline
\end{tabular}

Table 3: Malaria Parasitaemia among PEM and Non PEM 


\begin{tabular}{lll}
\hline Malaria parasitaemia & PEM n (\%) & Non PEM n (\%) \\
& & \\
\hline None & $8(8.9)$ & $78(86.7)$ \\
$+(1-10$ Parasite /100HPF) & $63(70)$ & $7(7.8)$ \\
$++(11-100$ Parasite /100HPF) & $18(20)$ & $5(5.0)$ \\
$+++(1-10$ parasites/ HPF) & $1(1.1)$ & None \\
Total & $\mathbf{9 0}(\mathbf{1 0 0})$ & $\mathbf{9 0}(\mathbf{1 0 0})$ \\
\hline & & \\
$\mathbf{2}=\mathbf{1 0 9 . 2 4} \quad \boldsymbol{p}=\mathbf{0 . 0 0 0 0}$ & OR $\mathbf{6 6 . 6 2 5}$ &
\end{tabular}

Table 4: Malaria Parasitaemia among various forms of PEM

\begin{tabular}{llllll}
\hline \multicolumn{1}{c}{ Malaria Parasite } & Kwashiokor & MarasmicKwashiokor & Marasmus & Underweight & $\begin{array}{l}\text { Total } \\
(\boldsymbol{\%})\end{array}$ \\
\hline None & 0 & 0 & 2 & 6 & $8(8.9)$ \\
$+(1-10$ Parasite /100HPF) & 3 & 7 & 14 & 39 & $63(70)$ \\
$++(11-100$ Parasite /100HPF) & 8 & 0 & 5 & 5 & $18(20)$ \\
$+++(1-10$ parasites/ HPF) & 0 & 1 & 0 & 0 & $1(1.1)$ \\
Total & $\mathbf{1 1}$ & $\mathbf{8}$ & $\mathbf{2 1}$ & $\mathbf{5 0}$ & $\mathbf{9 0}(\mathbf{1 0 0})$ \\
\hline
\end{tabular}

$\chi^{2}=35.75 \quad p=0.0000 \quad H P F=$ High power field 